\title{
Application of Buoy Observations in Determining Characteristics of Several Typhoons Passing the East China Sea in August 2012
}

\author{
Ningli Huang, ${ }^{1}$ Zheqing Fang, ${ }^{2}$ and Fei Liu' \\ ${ }^{1}$ Shanghai Marine Meteorological Center, Shanghai, China \\ ${ }^{2}$ Department of Atmospheric Science, Nanjing University, Nanjing, China \\ Correspondence should be addressed to Zheqing Fang; fangzheq@163.com
}

Received 27 February 2013; Revised 5 May 2013; Accepted 21 May 2013

Academic Editor: Lian Xie

Copyright ( $\odot 2013$ Ningli Huang et al. This is an open access article distributed under the Creative Commons Attribution License, which permits unrestricted use, distribution, and reproduction in any medium, provided the original work is properly cited.

The buoy observation network in the East China Sea is used to assist the determination of the characteristics of tropical cyclone structure in August 2012. When super typhoon "Haikui" made landfall in northern Zhejiang province, it passed over three buoys, the East China Sea Buoy, the Sea Reef Buoy, and the Channel Buoy, which were located within the radii of the $13.9 \mathrm{~m} / \mathrm{s}$ winds, $24.5 \mathrm{~m} / \mathrm{s}$ winds, and $24.5 \mathrm{~m} / \mathrm{s}$ winds, respectively. These buoy observations verified the accuracy of typhoon intensity determined by China Meteorological Administration (CMA). The East China Sea Buoy had closely observed typhoons "Bolaven" and "Tembin," which provided real-time guidance for forecasters to better understand the typhoon structure and were also used to quantify the air-sea interface heat exchange during the passage of the storm. The buoy-measured wind and pressure time series were also used to correct the intensity of "Damrey" initially determined by CMA.

\section{Introduction}

More tropical cyclones form in the tropical western North Pacific than anywhere else in the world. There are 863 tropical cyclones developed in 1970-2001. On average, 27 tropical storms developed each year, and about 18 become typhoons as discussed by Li et al. [1]. Each year an average of five typhoons generate maximum winds over 130 knots; circulations covering more than 600 miles in diameter are not uncommon. These typhoons are the largest and most intense tropical cyclones in the world and the frequency of landfall on East China area is increasing as discussed by Chen [2]. By the end of August 2012, 15 tropical cyclones developed over the Western North Pacific and the South China Sea, setting a new historical record for this region during the same time period. In addition to two typhoons which made landfall in southern China in July, there were 5 typhoons named "Saola," "Damrey," "Haikui," "Tembin," and "Bolaven" (see Figure 1), respectively, striking China in August, among which typhoon "Haikui" had a significant influence on East China coastal area due to its proximity to land.
The in situ observation network established by Shanghai Marine Meteorological Center covers the near shore area off Shanghai and the coastal waters of the East China Sea. It contains three $10 \mathrm{~m}$ discus buoys, one $3 \mathrm{~m}$ discus buoy, 3 ship-shaped buoys and 24 island stations as well as other conventional observing platforms over land. These $10 \mathrm{~m}$ discus buoys were "Channel Buoy" (30.55N, 122.38E), "Sea Reef Buoy" (30.41N, 122.93E), and "East China Sea Buoy" $(31 \mathrm{~N}, 124.5 \mathrm{E})$. All of them were in the paths of 3 typhoons during the active typhoon season of 2012. The applications of the buoy data collected during August 2012 in determination of typhoon intensity, size, and structure as well as real-time forecast verification are presented in this study.

\section{Size Identification of Typhoon Haikui by Buoy Data}

One of the major applications of buoy data is to validate typhoon sizes analyzed by different institutions. Typhoon Haikui is the first one which Chinese buoy network has observed the whole landfall process, and fortunately, the 
TABLE 1: CMA's Classification of tropical cyclones for Western North Pacific.

\begin{tabular}{lcc}
\hline $\begin{array}{l}\text { Grade of tropical } \\
\text { cyclones }\end{array}$ & $\begin{array}{c}\text { Maximum } \\
\text { sustained } \\
\text { (2-minute average) } \\
\text { wind speeds (m/s) }\end{array}$ & $\begin{array}{c}\text { Maximum surface } \\
\text { wind in beaufort } \\
\text { wind scale }\end{array}$ \\
\hline Tropical depression & $10.8 \sim 17.1$ & $6 \sim 7$ \\
Tropical storm & $17.2 \sim 24.4$ & $8 \sim 9$ \\
Severe tropical storm & $24.5 \sim 32.6$ & $10 \sim 11$ \\
Typhoon & $32.7 \sim 41.4$ & $12 \sim 13$ \\
Severe typhoon & $41.5 \sim 50.9$ & $14 \sim 15$ \\
Super typhoon & $\geqq 51.0$ & $\geqq 16$ \\
\hline
\end{tabular}

results have good consistence with forecasters' subjective analysis.

The CMA tropical cyclone intensity scale in the western North Pacific basin is based upon the maximum sustained (2-minute average) surface (10 meter) wind speeds (Table 1$)$ as defined by the national standard document [3].

Beaufort Wind Scale developed in 1805 by Sir Francis Beaufort of England [4] is used in operation of CMA. The 7th and 10th levels on the Beaufort Scale are used to represent the maximum sustained wind extent, which are more than $13.9 \mathrm{~m} / \mathrm{s}$ and $24.5 \mathrm{~m} / \mathrm{s}$, respectively. The radius of the area of the maximum sustained wind has a great relationship with typhoon intensity and the expected damage as measured by Saffir/Simpson scale [5].

In Figure 2 the Morphed Integrated Microwave Imagery at CIMSS (MIMIC) image of Typhoon Haikui is used to reveal the structure of the eye wall and precipitation distribution as discussed by Wimmers and Velden [6]. Before the landfall typhoon Haikui has an almost integral structure, the precipitation is concentrated in the eye wall and 1, 4 quadrant of the whole cyclone. Shanghai and Zhejiang province suffered heavy rainfall during this landfall process. Some island stations observed maximum winds exceeding $41.5 \mathrm{~m} / \mathrm{s}$ in the 14th level of Beaufort Wind Scale based on winds observed at about $100 \mathrm{~m}$. Since the $10 \mathrm{~m}$ discus buoys observe winds at $10 \mathrm{~m}$ height directly (conversion of winds between different heights can thus be omitted), the measured winds can be used to determine wind radius. East China Sea Buoy, Sea Reef Buoy, and Channel Buoy were located, respectively, out of the radii of the $13.9 \mathrm{~m} / \mathrm{s}$ winds, out of the radii of $24.5 \mathrm{~m} / \mathrm{s}$ winds and in the radii of $24.5 \mathrm{~m} / \mathrm{s}$ winds at 18:30 UTC. Buoys network can provide the real-time observation to assist and verify the wind radius to improve the typhoon intensity forecast. With their observations in Figure 3 all these data have great consistence with the typhoon maximum sustained wind circle identification by CMA.

The distance between the typhoon center and Sea Reef Buoy is $190 \mathrm{~km}$, very close but out of the radii of $24.5 \mathrm{~m} / \mathrm{s}$ winds, and 7-8th level maximum sustained wind speed was observed. The distance between typhoon center and the East China Sea Buoy is more than $400 \mathrm{~km}$, out of the radii of

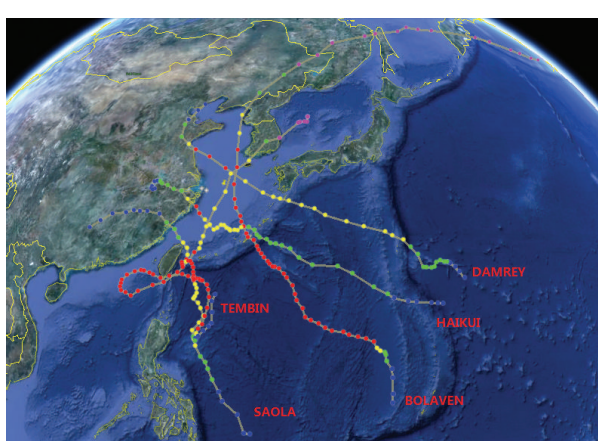

(a)

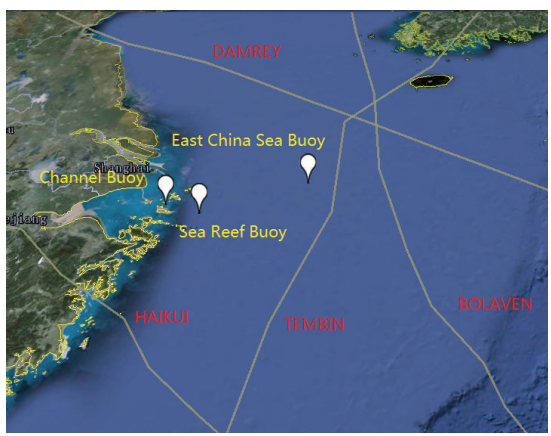

(b)

FIGURE 1: Typhoon information (source: http://agora.ex.nii.ac.jp/ digital-typhoon $/ \mathrm{kml} /$ ) with buoy location on Google Earth.

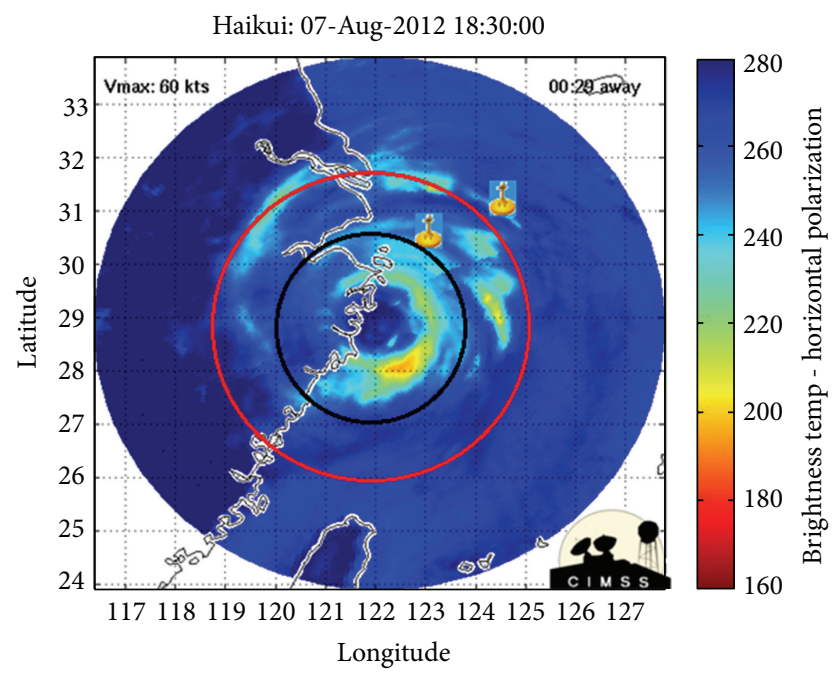

FIgURE 2: The Morphed Integrated Microwave Imagery at CIMSS (MIMIC) image of Typhoon Haikui and wind radius demonstration (black cycle indicates the radii of the 50-knot winds, and the red cycle indicates the radii of the 34 -knot winds) and buoy location.

$13.9 \mathrm{~m} / \mathrm{s}$ winds, and the observed wind speed was close to the 7 th level on the Beaufort Scale.

Figure 3(c) shows that during the landfall of typhoon Haikui, the Channel Buoy experienced persistent strong winds; the maximum sustained wind speed reached 8-9th level of Beaufort Wind Scale, and gust wind speed reached 
up to 9-11th level high. At the beginning of typhoon landfall, Channel Buoy was in the radii of $24.5 \mathrm{~m} / \mathrm{s}$ winds; after the wind direction shift to southeast, the observed wind speed was continuously increasing. While the southeast wind is in the same direction with the navigation channel, the additional funneling effect as discussed by Gao et al. [7] broke the anchor chain of the buoy at 11 a.m. August 8th in Local Time $(\mathrm{UTC}+8)$. The Channel Buoy floated with the wind and finally piled up at the beach of Feng Xian National Park. When the buoy was floating, the solar energy battery was still in operation and supplied the meteorological sensor to collect data as a drift buoy.

Comparing with other observations by the ship-shaped buoys in Figure 4, we can find that although the ship-shaped buoy in the Yangtze River estuary is near the Sea Reef Buoy, the onshore wind speed in near shore area reached about 8th level average and 10th level maximum, which was stronger than the wind observed by the Sea Reef Buoy.

According to the analysis of the 60 hours of buoy network observations, during typhoon landfall process, we can summarize that (1) the maximum wind radius of typhoon Haikui identified by CMA which is consistent with buoy observation at the time of landfall; Sea Reef Buoy and East China Sea Buoy were out of the wind circle, and Channel Buoy and other shipshaped buoys were within the wind circle; (2) when wind is blowing onshore or where Terrain funneling effect exists, winds are stronger. Kauai ship-shaped buoy is located about the same distance from the typhoon center as the Sea Reef Buoy, but the observed wind speed is larger; (3) the observed gust wind speed is approximately 1.4 times the calculated maximum sustained wind speeds consistent with the findings discussed by Atkinson and Holliday [8].

\section{Continuous Measurements Recorded by the East China Sea Buoy for Two Typhoons}

After typhoon Haikui struck East China, Typhoon Bolaven (number 1215) and typhoon Tembin (number 1214) moved across East China Sea in succession. Their tracks were influenced by the Fujiwhara effect as discussed by Fujiwhara [9] and provided a historical opportunity for continuously monitoring interaction of double typhoons from buoys.

According to Lander and Holland [10] when two cyclones are in proximity of one another, their centers will begin orbiting cyclonically about a point between the two systems due to their cyclonic wind circulations. The two vortices will be attracted to each other and eventually spiral into the center point and merge. It has not been agreed upon whether this is due to the divergent portion of the wind or vorticity advection. When the two vortices are of unequal size, the larger vortex will tend to dominate the interaction, and the smaller vortex will orbit around it.

As Tembin was lacking steering current, it slowed down on August 22nd 00UTC then shifted to the west. We found that the northward and eastward jump of the subtropical high led to the path of Bolaven shift northward two times. At the second time Bolaven shifted to the northwest, and Tembin was changing direction to southwest on August 25th

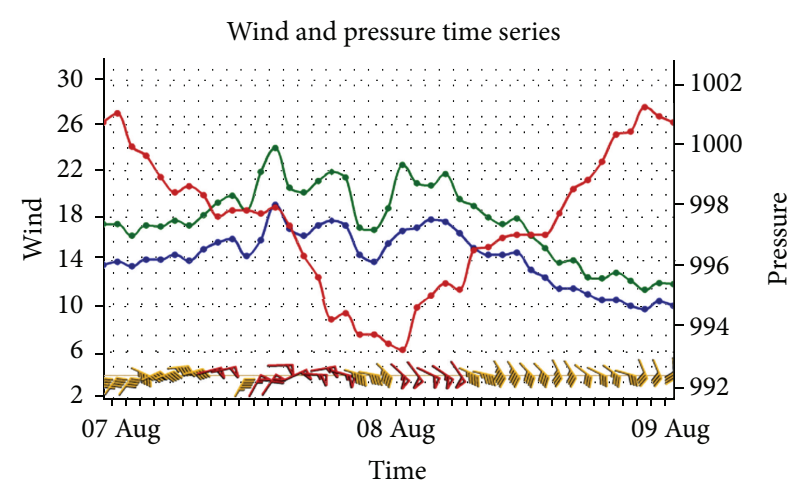

(a) Sea Reef Buoy

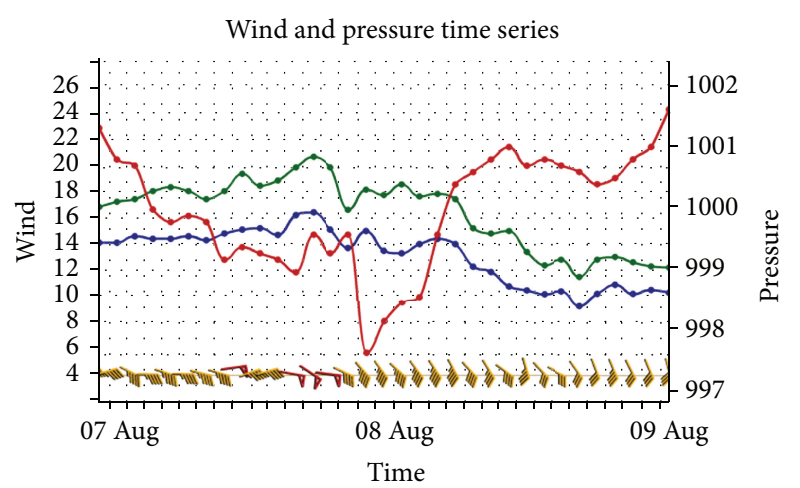

(b) East China Sea Buoy

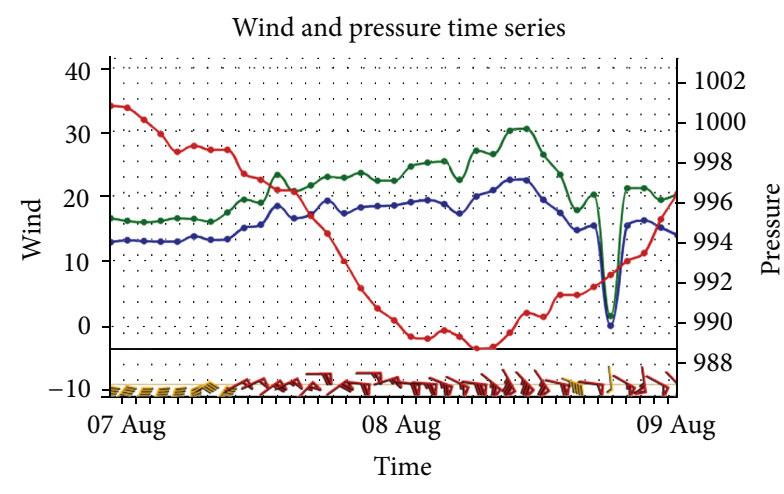

$\circ$ Maximum wind $(\mathrm{m} / \mathrm{s})$
$\circ$ Average wind $(\mathrm{m} / \mathrm{s})$
$\circ$ Pressure $(\mathrm{hPa})$

(c) Channel Buoy

FIGURE 3: The wind and pressure time series observed by $10 \mathrm{~m}$ discus buoys.

06UTC; this was mainly due to the cyclone's internal force and weak circulation produced by the two systems. When Bolaven moved northward on August 26th 18UTC, Tembin has reacted to shift to the east. After the subtropical high combined with the tropical high, the long distance south steering current led typhoon Tembin to move northward rapidly on August 28th 12UTC, following typhoon Bolaven and made landfall in the Korean Peninsula one after another. 


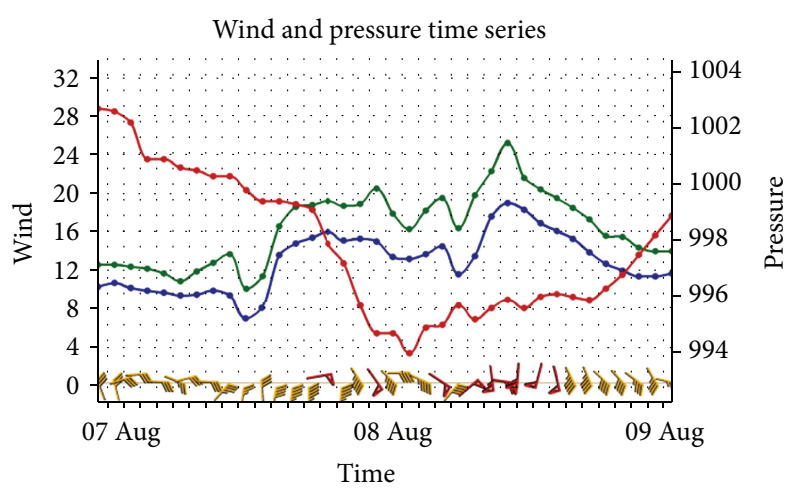

- Maximum wind $(\mathrm{m} / \mathrm{s})$

$\circ$ Average wind $(\mathrm{m} / \mathrm{s})$

- Pressure (hPa)

Figure 4: The wind and pressure time series observed by shipshaped buoy in Yangtze River estuary.

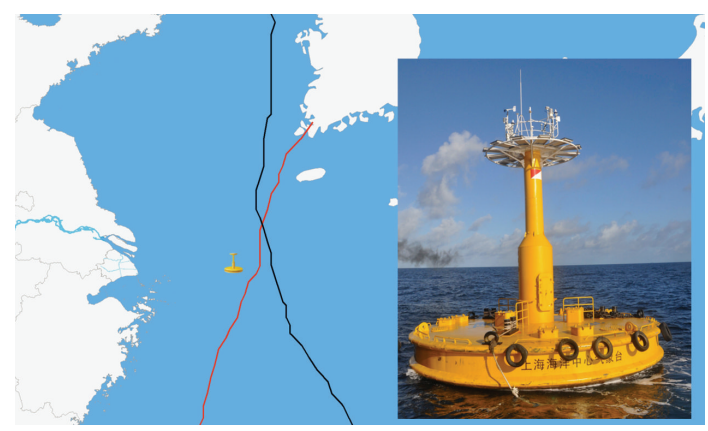

Figure 5: Two typhoons' tracks and the position of East China Sea Buoy. (Black line is the track of typhoon Bolaven and the red line is the track of typhoon Tembin.)

As a result, we can find in Figure 5 that the location of East China Sea Buoy is $31^{\circ} \mathrm{N}, 124.5^{\circ} \mathrm{E}$. The distance between the buoy and typhoon Bolaven was $110 \mathrm{~km}$, between the buoy and Tembin was $50 \mathrm{~km}$. The buoy was within the radii of the $24.5 \mathrm{~m} / \mathrm{s}$ winds of these two typhoon, thus can reveal their eye wall and core structure.

Typhoon Bolaven was a medium-large scale tropical cyclone, and when it passed over the East China Sea Buoy, it had the typhoon intensity, and the eye wall was obvious, with a diameter of about $200 \mathrm{~km}$. The buoy was located about $100 \mathrm{~km}$ from the storm center; so, it was right in the eye wall region. In Figure 6, we can see that between August 27th and August 28th, the East China Sea Buoy obtained the typical patterns such as the "V-shape" pressure curve and the "M-shape" wind curve. Comparing with the wind curve of typhoon Tembin on the right of the image, the two peaks of " $\mathrm{M}$-shape" wind curve are much smaller than Bolaven's. This comparison illustrates clearly that typhoon Bolaven has a large size of eye. At the bottom of Figure 6(a) is the wind bars, due to the dense observation, it may be hard to recognize but the red color indicates the wind speed more than $20 \mathrm{~m} / \mathrm{s}$; so, the core area of Bolaven has a large range of strong wind, and the maximum gust wind speed observed reached almost $40 \mathrm{~m} / \mathrm{s}$. Before the

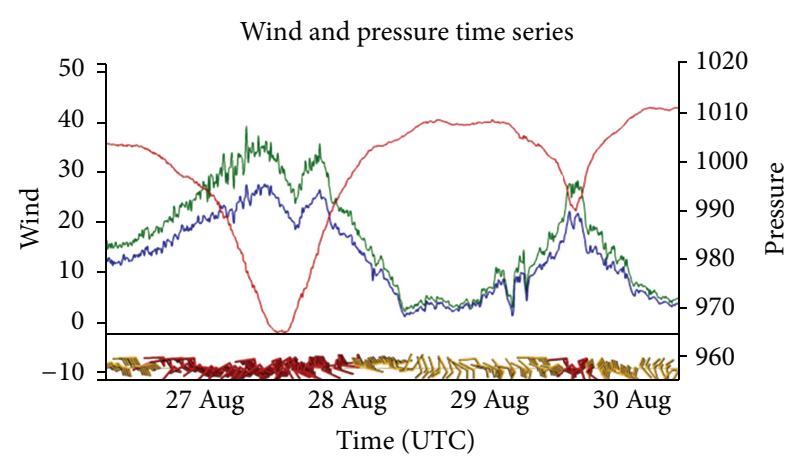

$$
\begin{aligned}
& \circ \text { Maximum wind }(\mathrm{m} / \mathrm{s}) \\
& \circ \text { Average wind }(\mathrm{m} / \mathrm{s}) \\
& \circ \text { Pressure }(\mathrm{hPa})
\end{aligned}
$$

(a) East China Sea Buoy

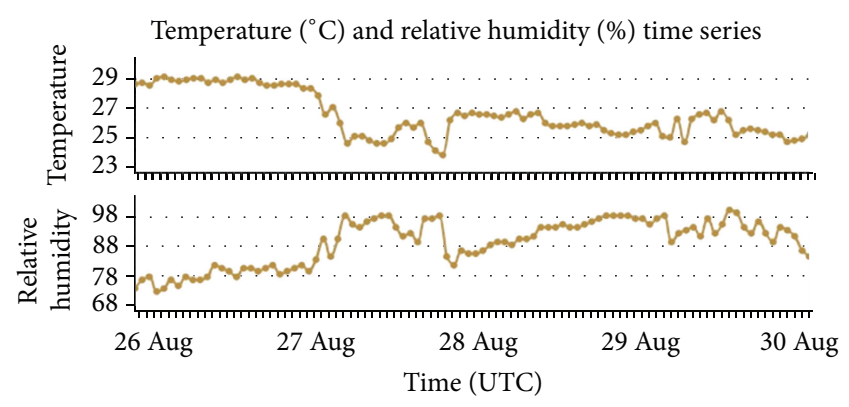

(b)

FIgURE 6: Two typhoon continuous measurement record by East China Sea Buoy ((a) is the wind and pressure time series, (b) is the temperature in unit ${ }^{\circ} \mathrm{C}$ and relative humidity time series).

center of the typhoon reached the same latitude with East China Sea Buoy, we observed that the maximum wave height was $14.4 \mathrm{~m}$. It was the highest wave record that East China Sea Buoy observed. Three hours later, the minimum sea level pressure reached $965 \mathrm{hPa}$. These results further confirmed that the typhoon has the characteristics of a large size of eye.

When Bolaven moves northward, the moisture conditions and strength are both weakened, because Tembin blocked part of the transportation of the water vapor from the low-latitude ocean. It affected the water vapor flux and the water vapor flux divergence of Bolaven and resulted in the asymmetric characteristics of the storm, characterized by a dry region to the west and a wet region to the east. The increase of vertical wind shear weakened typhoon Bolaven. The intrusion of the cold and dry air from the northwest area and the northwest-southeast distribution characteristics of the sea surface temperature gradient at East China Sea led the typhoon to show the structural characteristics of a more intense east part and weaker west part.

Next, consider the temperature and relative humidity time series. The rapid decrease of air temperature shows the presence of intensive air-sea interface heat exchange. Due to the dry air to the west, the humidity observed by the buoy was 
about 78\% before typhoon Bolaven passed over. However, for typhoon Tembin, the humidity was observed as almost $98 \%$. The temperature also showed more variation when Bolaven passed but almost unchanged when Tembin passed. These results are in good agreement with the findings discussed by $\mathrm{Wu}$ et al. [11]. In their study, it is shown that the air-sea interface heat exchange is very strong during the passage of a typhoon. The main contribution to the heat is from latent heat fluxes. In the circumfluence of the typhoon, both of the water temperature and the air temperature dropped. The air temperature dropped more obviously. In the circumfluence of the typhoon, absorbing short wave radiation by the sea surface becomes weaker, and the effect from relative humidity on the air-sea interface heat exchange is obvious. When the typhoon is affected by cold air, sensible heat can be important as well. The main temperature trend follows that of SST. In summary, our continuous observation of two typhoons supports the notion that large air-sea interface heat exchange occurs in low humidity region, and weaker air-sea heat exchange occurs in regions of high humidity.

When Tembin was close to East China Sea Buoy, the distance between buoy and the center of Tembin is less than $50 \mathrm{~km}$; so, Tembin was the closest typhoon observed by the East China Sea Buoy. When tropical storm Tembin reached $30^{\circ} \mathrm{N}$ latitude, it intensified to a typhoon status again, but it had a small eye. The CMA subjective forecast indicated that the $24.5 \mathrm{~m} / \mathrm{s}$ wind circle was $70 \mathrm{~km}$ which contained the location of the East China Sea Buoy. However, the CMA forecast was inconsistent with buoy observations. As shown in Figure 6, the buoy observations indicated that the maximum wind speed at the time was only at level 8-9 suggesting that Tembin was smaller than CMA's forecast.

\section{Improve the Understanding of Typhoon Damrey through Buoy Observation}

It was such a coincidence that two typhoons were named in the same day and made landfall in China still in the same day. Typhoon Saola and Damrey were named on July 28th. Typhoon Saola is a super typhoon and made landfall during high astronomic tide which resulted in serious inundation along the coast of Fujian province caused by the effect of large storm surge and tide. Typhoons Saola and Damrey became a large circulation and experienced the Fujiwhara effect.

Damrey was the first typhoon that passed close to the East China Sea Buoy, and it was a small-size high-intensity and fast-moving storm. After it made landfall at Tanegashima Island in Japan it moved northwestward into the Yellow Sea and the intensity was increasing until the second landfall in northern Jiangsu province in China. This high latitude westward-moving typhoon is a very rare event.

Due to the complicated interaction and unusual track, it was very hard to determine the impact on the high latitude city such as Jiangsu near shore area. CMA issued a forecast indicating that the radius of $13.9 \mathrm{~m} / \mathrm{s}$ wind speed would become $200 \mathrm{~km}$ at 12UTC on August 1st. However, as we can see from Figure 7 that at 00UTC on August 2nd, the wind at the East China Sea buoy did not reach $13.9 \mathrm{~m} / \mathrm{s}$ although

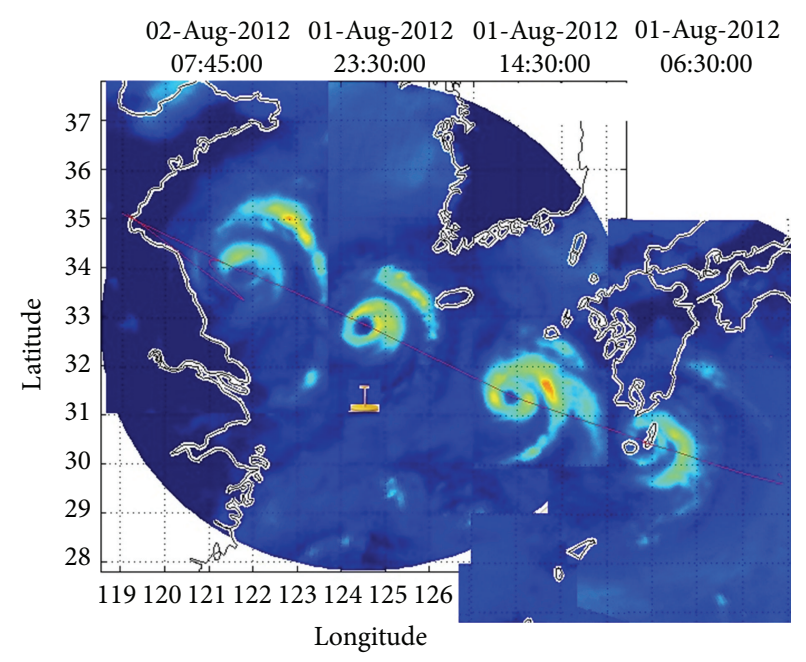

(a)

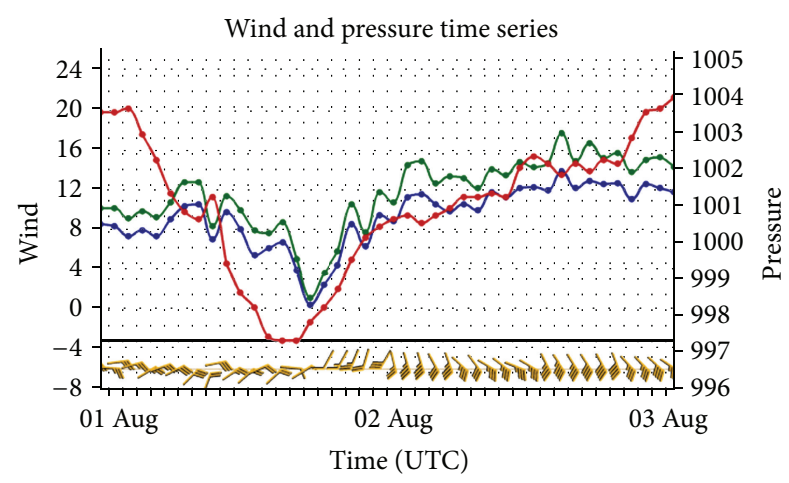

$\circ$ Maximum wind $(\mathrm{m} / \mathrm{s})$
$\circ$ Average wind $(\mathrm{m} / \mathrm{s})$
$\circ$ Pressure $(\mathrm{hPa})$

(b)

FIgure 7: Typhoon Damrey's track, spliced MIMIC images by authors, with the position of East China Sea Buoy and the wind-pressure time series.

the distance between the Buoy and Damrey was only $150 \mathrm{~km}$. This observation was used to correct the CMA forecast in subsequent hours. It is worth noting that the observed wind was still increasing after typhoon Damrey passed over the buoy. This is likely because typhoon Saola was a mediumlarge scale typhoon and Damrey is in its inverted trough.

\section{Conclusion}

After the establishment of Shanghai Marine Meteorological Center in 2009, the deployments of in situ marine and weather monitoring stations based on buoys and island stations have steadily increased over the East China Sea. Realtime observations from these marine and island-observing stations improved the understanding of hazardous marine weather in the East China Sea for marine weather forecasters in operational weather forecasting. In this paper, we presented the applications of marine buoy observations in 
the typhoon size and intensity forecasting during August 2012. The results show that real-time buoy data can be used in operational applications in at least three ways: (1) validate the size identification made by different weather forecast centers, as it is illustrated for the case of typhoon Haikui; (2) validate the theories on air-sea interaction in typhoon processes, as illustrated by the cases of typhoons Bolaven and Tembin concerning double typhoon behavior as well as air-sea fluxes resulting from the inhomogeneity of moisture content in the typhoon system; (3) Improve the understanding of the weather system and the characteristics of its circulation in near real time, as illustrated for the cases of typhoons Saola and Damrey.

In addition to the real-time applications discussed above, buoy observations also have broad applications in areas such as numerical weather prediction through data assimilation, wind field evaluation in marine environment, marine atmospheric boundary layer and oceanic mixed layer dynamics, and satellite scatterometer validation. As we expand our marine monitoring network with additional monitoring stations and more advanced instruments such as sonic anemometer, wind profiler, drifting buoys, and coastal radar, it will open the way for new discoveries and improve hazardous marine weather forecasts.

\section{References}

[1] Y. Li, L. Chen, and S. Zhang, "Statistical characteristics of tropical cyclone making landfalls on China," Journal of Tropical Meteorology, vol. 20, pp. 14-23, 2004.

[2] L. Chen, "Tropical meteorological calamities and its research evalution," Meteorological Monthly, vol. 36, pp. 101-110, 2010.

[3] “China, N. S. o. t. P. s. R. o. Grade of Tropical Cyclones," GB/T, 19201-2006., 2006.

[4] "The Beaufort wind scale," Monthly Weather Review, vol. 42, Article ID 232, p. 231, 1914.

[5] R. H. Simpson, “The hurricane disaster potential scale," Weatherwise, vol. 27, no. 4, pp. 169-186, 1974.

[6] A. J. Wimmers and C. S. Velden, "MIMIC: a new approach to visualizing satellite microwave imagery of tropical cyclones," Bulletin of the American Meteorological Society, vol. 88, no. 8, pp. 1187-1196, 2007.

[7] S. Gao, X. Wu, and X. He, "Analysis of characteristics and formation of offshore wind field in Fujian influenced by 1010 typhoon Meranti," Journal of Oceanography in Taiwan Strait, vol. 31, pp. 173-181, 2012.

[8] G. D. Atkinson and C. R. Holliday, "Tropical cyclone minimum sea level pressure/maximum sustained wind relationship for the Western North Pacific," Monthly Weather Review, vol. 105, pp. 421-427, 1977.

[9] S. Fujiwhara, "The natural tendency towards symmetry of motion and its application as a principle in meteorology," Quarterly Journal of the Royal Meteorological Society, vol. 47, pp. 287293, 1921.

[10] M. Lander and G. J. Holland, "On the interaction of tropicalcyclone-scale vortices. I: observations," Quarterly Journal of the Royal Meteorological Society, vol. 119, no. 514, pp. 1347-1361, 1993.
[11] D. Wu, J. Wei, Y. Li, W. Zhang, and W. Wang, "A research on airsea interface heat exchange under the tropical cyclone," Scientia Meteorologlca Sinica, vol. 29, pp. 781-786, 2009. 

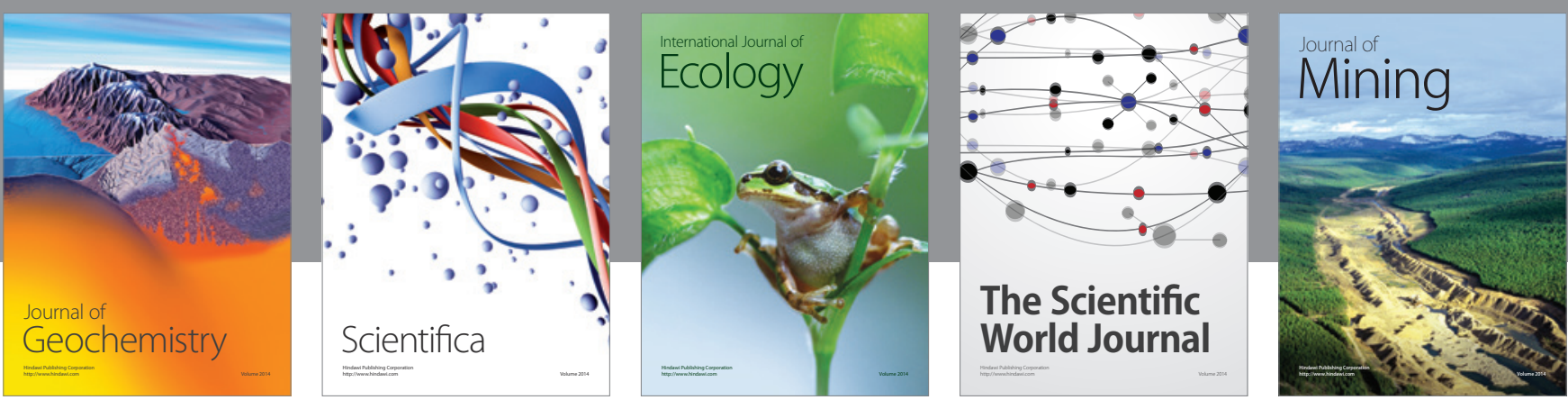

The Scientific World Journal
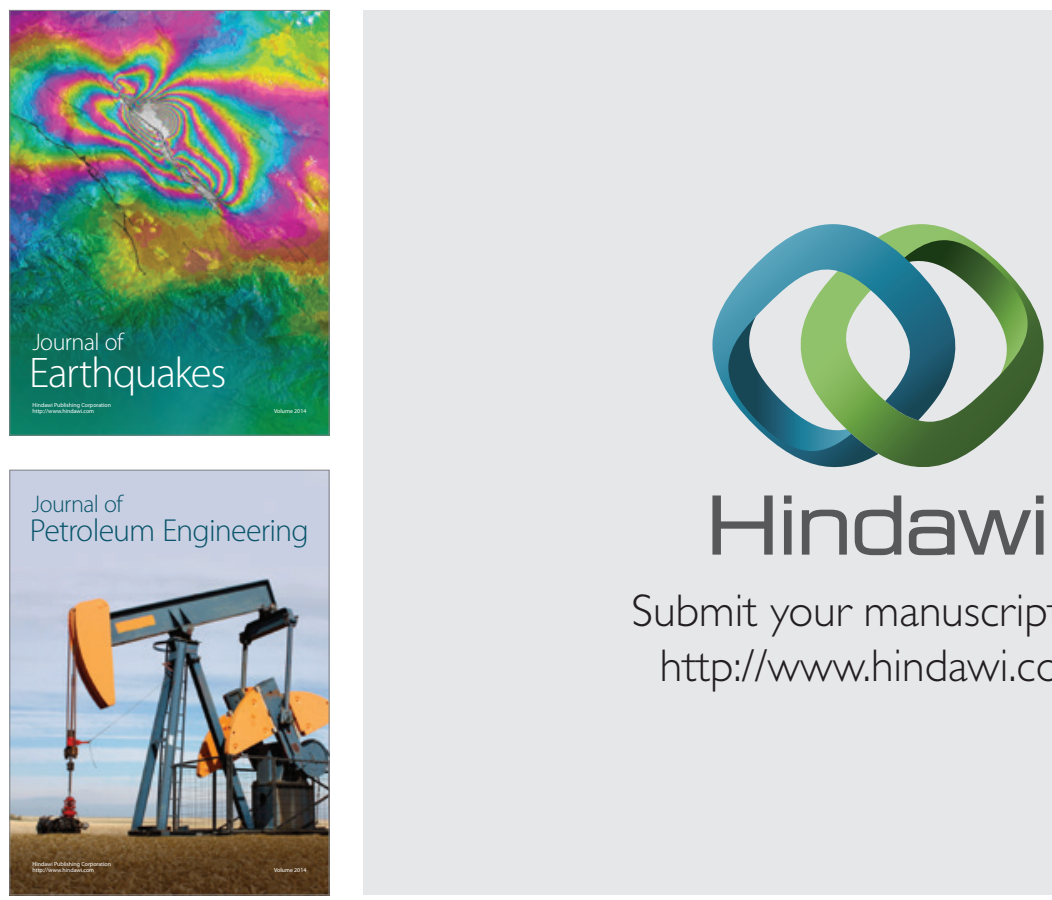

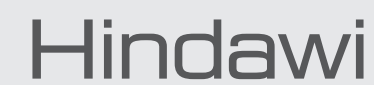

Submit your manuscripts at

http://www.hindawi.com

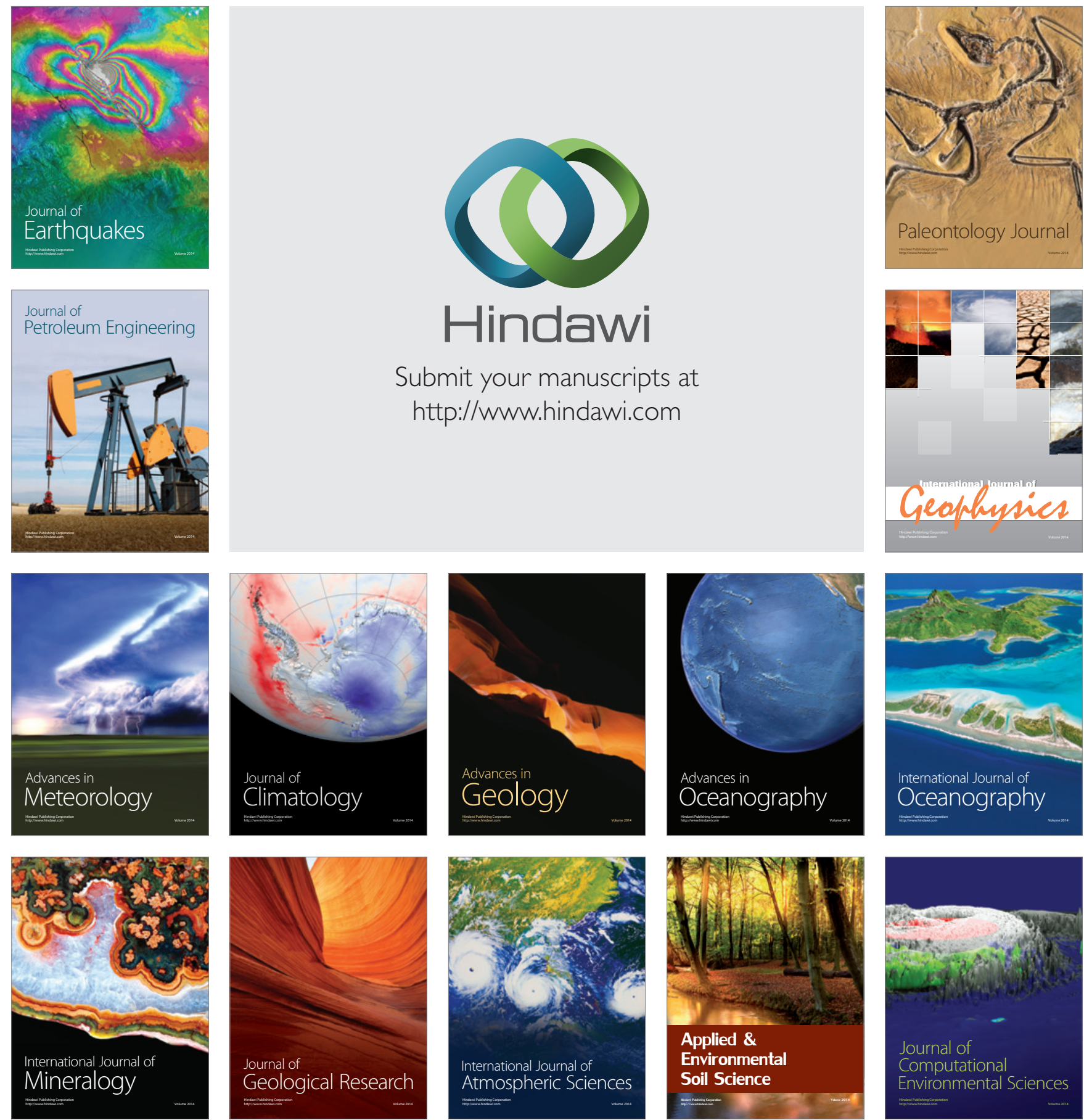